
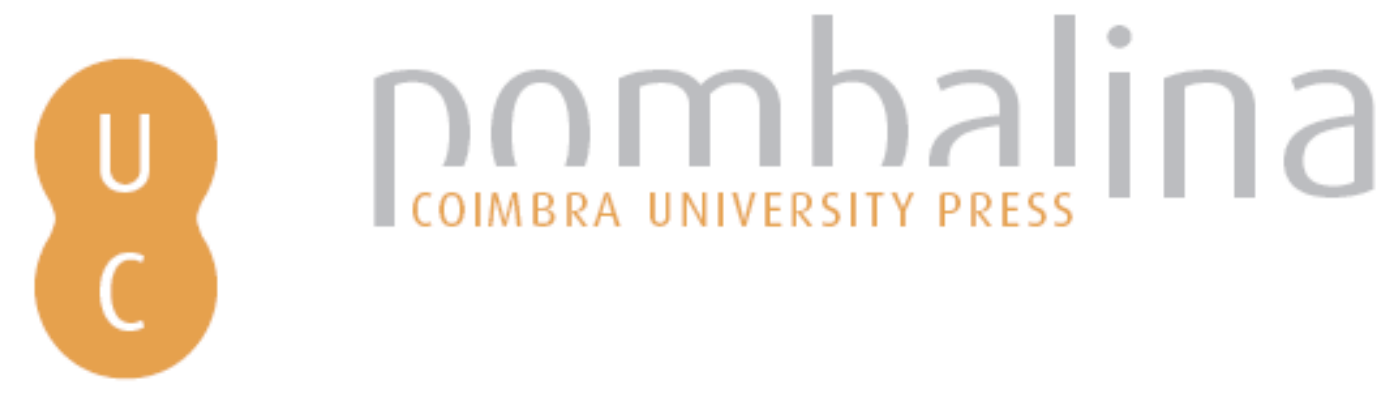

\title{
Peri Basilissas: em torno da importância política de cinco rainhas helenísticas
}

Autor(es): $\quad$ Rodrigues, Nuno Simões

Publicado por: Imprensa da Universidade de Coimbra

URL

persistente: URI:http://hdl.handle.net/10316.2/45223

DOI: $\quad$ DOI:https://doi.org/10.14195/978-989-26-1626-1_14

Accessed : $\quad$ 26-Apr-2023 16:21:30

A navegação consulta e descarregamento dos títulos inseridos nas Bibliotecas Digitais UC Digitalis, UC Pombalina e UC Impactum, pressupõem a aceitação plena e sem reservas dos Termos e Condições de Uso destas Bibliotecas Digitais, disponíveis em https://digitalis.uc.pt/pt-pt/termos.

Conforme exposto nos referidos Termos e Condições de Uso, o descarregamento de títulos de acesso restrito requer uma licença válida de autorização devendo o utilizador aceder ao(s) documento(s) a partir de um endereço de IP da instituição detentora da supramencionada licença.

Ao utilizador é apenas permitido o descarregamento para uso pessoal, pelo que o emprego do(s) título(s) descarregado(s) para outro fim, designadamente comercial, carece de autorização do respetivo autor ou editor da obra.

Na medida em que todas as obras da UC Digitalis se encontram protegidas pelo Código do Direito de Autor e Direitos Conexos e demais legislação aplicável, toda a cópia, parcial ou total, deste documento, nos casos em que é legalmente admitida, deverá conter ou fazer-se acompanhar por este aviso.

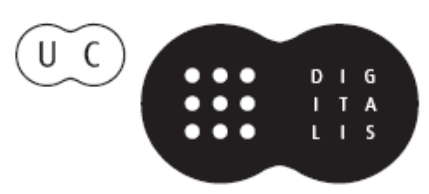




\section{Arqueologias de Império}

\section{Delfim Leão, José Augusto Ramos, Nuno Simões Rodrigues (coords.)}

IMPRENSA DA UNIVERSIDADE DE COIMBRA 


\title{
PERI BASILISSAS. EM TORNO DA IMPORTÂNCIA POLÍTICA DE CINCO RAINHAS HELENÍSTICAS ${ }^{1}$ \\ (Peri Basilissas. Regarding the political importance of five Hellenistic queens)
}

\author{
Nuno Simões Rodrigues \\ (nonnius@fl.ul.pt; ORCID: 0000-0001-6109-4096) \\ Universidade de Lisboa, Faculdade de Letras, CEC e CH-ULisboa, \\ Centro de Estudos Clássicos e Humanísticos da UC
}

\begin{abstract}
Resumo - Este ensaio visa refletir sobre o papel da mulher na sociedade helenística, especialmente no que diz respeito à esfera do poder, a partir do estudo de cinco casos: Olímpia do Epiro, Laódice I da Síria, Berenice I do Egito, Arsínoe II do Egito e Cleópatra VII do Egito.

Palavras-chave: Olímpia do Epiro; Laódice I da Síria; Berenice I do Egito; Arsínoe II do Egito; Cleópatra VII do Egito.

Aвstract - This essay aims to think about women's role in Hellenistic times and society, taking the sphere of power as specific context, through five case-studies: Olympias of Epirus, Laodice I of Syria, Berenice I of Egypt, Arsinoe II of Egypt and Cleopatra VII of Egypt.

KEYwORDs: Olympias of Epirus; Laodice I of Syria; Berenice I of Egypt; Arsinoe II of Egypt; Cleopatra VII of Egypt.
\end{abstract}

Durante o período helenístico, as figuras femininas ganham um lugar na literatura grega, designadamente na historiografia, que até então lhes estivera, se não vedado, pelo menos bastante condicionado. Isso dever-se-á, muito provavelmente, ao facto de, também no processo e vivência históricos, as mulheres terem conquistado um espaço de ação que até então lhes era estranho. Não temos, obviamente, a veleidade de pensar que a mulher grega comum terá alcançado nessa época um lugar de que fora até então constantemente afastada. Isso seria demasiado anacrónico. Mas parece-nos evidente que as rainhas helenísticas, em particular, enquanto membros das elites, surgem nas fontes da época com um protagonismo político que jamais alguma mulher grega conhecera, seja ele negativo ou positivo. Vejamos alguns exemplos.

\section{Olímpia do Epiro}

O primeiro caso emblemático desta «nova» realidade e forma de olhar o feminino é Olímpia, a mãe de Alexandre da Macedónia. Esta princesa do Epiro

\footnotetext{
${ }^{1}$ Este trabalho foi apoiado por Fundos Nacionais através da FCT - Fundação para a Ciência e a Tecnologia no âmbito do projeto UID/HIS/04311/2013 e do projeto UID/ELT/00196/2013.
} 
viveu entre c. 373 e 316 a. C. Muito provavelmente, a filha do rei Neoptólemo da Molóssia nasceu com o nome de Políxena, tendo sido renomeada Olímpia por Filipe da Macedónia, depois que ela lhe deu um filho varão, o que coincidiu com a vitória dos cavalos do marido, nos Jogos Olímpicos ${ }^{2}$. Este casamento aconteceu em 359 a.C., tendo-se Olímpia separado do soberano macedónio em 337 a.C., depois de ter dado à luz Alexandre e Cleópatra e na sequência de uma série de alegadas infidelidades conjugais por parte do marido. Olímpia autoexilou-se então no Epiro, com o filho Alexandre, ao mesmo tempo que Filipe celebrava um novo casamento, desta vez com uma mulher da nobreza macedónica, igualmente chamada Cleópatra. Por detrás da atitude da rainha e do filho dela deverá ter estado, muito por certo, o processo de sucessão do trono que os vários casamentos de Filipe determinavam e respetivas descendências almejavam. Após o assassínio de Filipe, em 336 a.C., que, para alguns, não terá sido estranho a Olímpia ${ }^{3}$ a basilissa encarregou-se de eliminar a sua rival Cleópatra, bem como os familiares dela mais influentes, e regressou ao reino do marido ${ }^{4}$. Depois de Alexandre ter partido para o Oriente, a regência da Macedónia foi assumida por Antípatro, mas Olímpia manteve-se influente na corte e, consequentemente, na política do reino. Enquanto Olímpia, porém, representava na Macedónia uma fação estrangeira, Antípatro e a sua família traduziam um partido autóctone, cuja oposição aos interesses da mãe de Alexandre, a julgar pelas cartas trocadas entre o general e Olímpia, ia crescendo significativamente ${ }^{5}$. Entre os argumentos que orientavam o partido macedónico incluía-se a ideia de que o controlo feminino dos destinos políticos do reino só poderia ser prejudicial para o Estado. Essa oposição levou a que, em 331 a.C., Olímpia retornasse ao Epiro, onde a filha Cleópatra era então a regente. Juntas, constituíram ali um partido de oposição ao governo de Antípatro, o qual era então coadjuvado pelo seu filho Cassandro.

Em 323 a.C., contudo, a morte de Alexandre, em Babilónia, provocou uma luta de poder sem precedentes entre a nobreza macedónica. Entre as fações em confronto encontrava-se a da própria Olímpia, cujo peso era tão grande quanto o de qualquer um dos diádocos. Enquanto os generais do rei dividiram entre si o território que se estendia da Grécia à Índia e ao Egito, o trono da Macedónia foi atribuído a um filho de Alexandre e de uma princesa da Sogdiana, chamada Roxana ${ }^{6}$. Tratava-se de um herdeiro mestiço, que cumpria um dos projetos do filho de Olímpia: a miscigenação entre orientais e europeus. Mas era essa

\footnotetext{
${ }^{2}$ Plu. Alex. 2; Moralia 401b. Sobre os vários nomes de Olímpia, ver Macurdy 1985, 24; Mirón 2002, 1617; Carney 2006, 15-17.

${ }^{3}$ Sobre esta questão ver Arist. Pol. 1311 b.

${ }^{4}$ Sobre o título de basilissa, ver Macurdy 1985, 8.

${ }^{5}$ Em parte, é o que podemos deduzir de passos como Plu. Alex. 27.8 e Gell. 13.4, nos quais lemos sobre as cartas trocadas entre mãe e filho. Ver nota 20.

${ }^{6}$ Waterfield 2011.
} 
mesma característica que fazia crescer focos de oposição entre os sectores grecomacedónicos mais conservadores, pelo que se nomeou um co-rei, Filipe Arrideu, meio-irmão de Alexandre. Sendo ambos os reis ainda crianças, Antípatro manteve a regência do país.

Em 319 a.C., os novos reis chegaram à Macedónia e pouco depois morria o regente. Foi, contudo, Poliperconte, e não o filho de Antípatro, Cassandro, quem lhe sucedeu na regência. Perante a resistência de Cassandro a essa escolha, Poliperconte solicitou a ajuda de Olímpia, fazendo-a regressar também à Macedónia. Esta atitude do novo regente é relevante do valor político que a mãe de Alexandre angariara entre os Macedónios, e não só. Cassandro, pelo seu lado, encontrou apoio em Ádea Eurídice, a mulher de Filipe Arrideu. Inteirando-se da situação, Olímpia fez-se acompanhar de um exército, com o qual defrontou o de Ádea Eurídice. O efetivo confronto bélico, todavia, nunca aconteceu, visto que os homens de Ádea se renderam e colocaram-se ao lado de Olímpia, aparentemente impressionados pela majestade dela. O testemunho de Dúris dá conta de duas mulheres que aparecem no campo de batalha, equipadas com as armas que melhor dominavam: Ádea Eurídice envergando uma armadura macedónica, visto que havia sido militarmente treinada, enquanto Olímpia surgia como uma ménade, avançando à frente do seu exército, tocando uma flauta dionisíaca ${ }^{7}$. Como salienta D. Mirón, talvez aqueles soldados simplesmente não estivessem preparados para lidar com a chefia de uma mulher que se vestia «à homem», como se fosse uma amazona ${ }^{8}$. Mas não deixa de ser curiosa a adesão a uma outra, que representa a desmesura dionisíaca. Parece-nos evidente que estamos no domínio da historiografia patética, um estilo de texto historiográfico que se rege pela presença de categorias associadas a outros estilos poéticos, como o trágico, ou temas em que predominam as emoções dos intervenientes.

Tendo ganhado este confronto, Olímpia tratou de eliminar imediatamente a ameaça que Filipe Arrideu e Ádea Eurídice representavam para o exercício do seu poder. Nesse contexto, foram mesmo executados vários dos nobres macedónios que representavam oposição a Olímpia. Talvez tenha sido essa atitude que a fez perder apoios entre os Macedónios e aumentar os de Cassandro, pelo que a situação política de Olímpia no território agravou-se. Em 317 a.C., a rainha retirou-se para Pidna, juntamente com a sua corte, em que se incluíam Roxana e o filho dela, a enteada Tessalonica, a princesa epirota Deidamia, além de parentes e vários amigos ${ }^{9}$. Ao fim de um longo período de cerco e de

${ }^{7}$ Ath. 13.560 et sq. Sendo Ádea Eurídice descendente das aristocracias ilíricas, fora educada por sua mãe na tradição das artes militares, tal como acontecia com as mulheres da região e o que era estranho ao resto da Grécia. Ver Mirón 2002, 26; Carney 2006, 16, 44, 72-76, 84-85, 87, 96-97, 126-27, 129, 136.

${ }^{8}$ Mirón 2002, 27.

${ }^{9}$ Mirón 2002, 28. 
muitos desaires num eventual processo de ajuda, Olímpia reconheceu a derrota e entregou-se a Cassandro, acreditando que teria direito a viver ${ }^{10}$. Mas, depois de um julgamento, em que nem sequer esteve presente, Olímpia foi condenada à morte. $\mathrm{O}$ processo de execução da rainha também não foi pacífico e apenas quando recorreu aos familiares das vítimas de Olímpia, Cassandro conseguiu a execução da mãe de Alexandre Magno ${ }^{11}$.

É em Diodoro Sículo, autor contemporâneo de Augusto, e em Plutarco, que viveu na transição do século I para o século II, que encontramos as principais referências a Olímpia do Epiro. Mas, apesar de relativamente tardios, no que diz respeito à proximidade cronológica com a personagem em causa, Diodoro e Plutarco deverão refletir uma tradição que terá também dado origem às fontes em que radicam as suas informações. Muitos dos elementos a que estes dois autores gregos recorrem para compor a figura de Olímpia coincidem na tónica que derivará não apenas da exatidão da "verdade histórica», mas também de uma «ideia» de Olímpia, que se terá construído na historiografia clássica e que foi sucessivamente retransmitida.

A figura da «mãe» domina o carácter desta mulher. De facto, em grande parte, ela existe apenas pela relação com o filho Alexandre. Apesar disso, é inegável que Olímpia ganha, por momentos, direito a um protagonismo autónomo, designadamente no que diz respeito à luta que enceta pelo domínio do reino macedónico. Ao que parece, no Epiro, as mulheres gozavam de uma liberdade relativamente maior do que acontecia nas cidades gregas do Sul ou até mesmo na Macedónia, e o papel das rainhas-mães, como mostra o caso de Olímpia, aponta para essa realidade ${ }^{12}$. Estar-se-á assim em consonância com o que acontecia no Oriente? Muito provavelmente. Aí, era comum o soberano ser sucedido, de uma forma consuetudinária, pelo filho varão mais velho. Mas nem sempre isso acontecia de forma pacífica. Muitas vezes, os atos de poligamia ou o repúdio de uma rainha levavam a que os seus filhos fossem preteridos, em favor dos descendentes de uma segunda ou terceira mulher, a quem o rei se unisse. Criavam-se assim as condições para uma luta de sucessão, na qual o papel das rainhas-mães se revelava essencial. De facto, a prová-lo, encontramos o caso de Ahatmilku, rainha de Ugarit, que chefiou uma luta para que, após a morte do rei Niquemepa, seu marido, lhe sucedesse um filho seu; o da rainha hitita Puduhepa, esposa de Hुattušili III; o de Tii e Nefertiti, no Egito; os de Haguite e Betsabé, que após a morte de David defenderam, cada qual, os seus interesses nas pessoas dos seus filhos, ambos candidatos ao trono

\footnotetext{
${ }^{10}$ D. S. $19.49-51$.

${ }^{11}$ Just. 14.6.9-11. Uma síntese da biografia de Olímpia pode ser lida em Macurdy 1985, 22-48; e em Carney 2000, 114-52; Carney 2006, 84.

${ }^{12} \mathrm{Na}$ verdade, já Eurídice, a mãe de Filipe, tinha agido de uma forma pouco normal para o que era hábito no contexto em causa.
} 
de Israel; o exemplo de Maaca, mãe do rei Abias ${ }^{13}$; ou ainda os de Neústa, mãe de Joiaquim ${ }^{14}$; Samuramat, rainha da Assíria e mãe de Adad-Nirari; Naqui'aZakuto, outra rainha assíria, mãe de Assaradão; Adad-Guppi, rainha babilónia, mãe de Nabónido; e Atossa da Pérsia, filha de Ciro, esposa de Dario e mãe de Xerxes $^{15}$. Um conjunto de mulheres que em certa medida intervieram e controlaram mesmo a política do Próximo Oriente Antigo, do século XIII ao $\mathrm{V}$ a.C. ${ }^{16}$ Alguns destes casos são mesmo testemunhados pelas fontes gregas, nomeadamente por Heródoto, cujas rainhas bárbaras são exemplo de práticas desta natureza ${ }^{17}$. Este quadro permite-nos aproximar a realidade da Macedónia do século IV a.C. do que ocorrera já antes nos territórios orientais.

Por outro lado, o facto de Olímpia reclamar uma ascendência mítica é sintoma de uma importância que se deseja acentuar, ainda que isso possa ser uma construção historiográfica feita a posteriori. Ao reclamar Tétis como sua antepassada, Olímpia tornava-se semelhante à mãe de Aquiles, com quem, por sua vez, o filho Alexandre fazia questão de se identificar (e.g. Plu. Alex. 5.7).

Quando comparado com o que conhecemos da restante Grécia, este elemento surge como uma peculiaridade, mas outra característica desta rainha da Macedónia é o facto de ser «estrangeira». Tanto o Epiro como a Macedónia pertenciam ao universo comum da Hélade, apesar das diferenças que os separavam e das que os afastavam das regiões gregas do Sul balcânico ou da Ásia Menor. Mas a unidade linguística era uma realidade, entre outras, a ter em conta e tanto os Epirotas como os Macedónios se consideravam membros dessa koine que formava o Mundo Helenístico. Ainda assim, em relação à Macedónia, o Epiro era tido como uma região estrangeira, com costumes distintos o bastante para se assinalar a diferença. A posição social e a função política das mulheres na comunidade seriam categorias através das quais se marcariam tais diferenças, levando Alexandre a afirmar que a mãe tinha escolhido bem ao colocar-se ao lado da fação que se refugiara no Epiro, visto que «os Macedónios jamais tolerariam ser governados por uma mulher ${ }^{18}$.

Além da afirmação explícita do carácter estrangeiro de Olímpia, outros elementos há que, nos historiadores antigos, permitem a definição da personalidade da rainha como alheia ao universo helénico em geral. Consideramos que entre esses elementos está o carácter politicamente emancipado, que fornece as coordenadas principais do retrato da mãe de Alexandre.

\footnotetext{
${ }^{13} 2$ Cr 11:21-22.

${ }^{14}$ 2Rs 24:8-16.

${ }^{15}$ Hdt. 7.2.3.

${ }^{16}$ Sobre esta questão, vide Tavares 1998, 15-28; Ben-Barak 1987, 30-52; Andreasen 1983,

${ }^{17}$ Ver Amaral 1994. Agradecemos às nossas colegas, Doutora Carmen Leal Soares e Doutora Ana Lúcia Amaral Curado, as sugestões que deram para esta parte do nosso estudo.

${ }^{18}$ Apud Mirón 2002, 24; cf. D. S. 19.11.
} 186-90. 
A atividade e iniciativa políticas da rainha surgem em quase todos os textos antigos que a mencionam. As manobras que leva a cabo para se apropriar do poder e as forças cuja chefia assume são disso evidência ${ }^{19}$. A atividade epistolar a ela associada aponta inclusive nesse sentido ${ }^{20}$. É também enquanto rainha-mãe que grande parte da sua imagem política se define. Qual sombra por detrás de Alexandre, Olímpia manobra forças e projeta objetivos ${ }^{21}$. As suas atitudes políticas revelam-se fundamentais no contexto em causa e Olímpia toma decisões que fatalmente condicionarão a sua imagem. A crueldade que demonstra ter ao aprisionar Filipe e Eurídice e as execuções que daí decorrem contribuem para definir o carácter da rainha, condicionando a sua imagem histórica. Justificase assim a sua morte inglória, se não mesmo indigna, como um castigo pelas crueldades e, até certo ponto, injustiças, que demonstrou para com os seus adversários políticos ${ }^{22}$. Esta acaba por ser uma imagem retoricamente definida pela ideia de crime/castigo ou, em termos comparatistas com a poética do trágico, hybris/nemesis. Tais ações inscrevem-se num quadro de categorias, cuja evocação literário-historiográfica estava em voga desde o século $\mathrm{V}$ a.C., e em particular nos dois primeiros séculos do Império, em que determinadas características para uma representação positiva ou negativa da personalidade que se pretendia construir eram particularmente evidenciadas. Neste caso concreto, o retrato de Olímpia passa por um crivo em grande parte de influência estoica, em que a exibição do furor, por exemplo, em nada contribui para a sua dignificação enquanto femina politica ${ }^{23}$. Aliás, esta mesma ideia é, por si só, pejorativa no contexto em causa. Esse furor, contudo, contrasta com a sensatez de uma resposta irónica como a que podemos ler em Aulo Gélio e em Plutarco: como Alexandre tinha escrito uma carta à mãe em que se autointitulava filho de Zeus Ámon, a rainha ter-lhe-á respondido: «Peço-te, filho, que te cales e que não me difames ou me acuses perante Hera; pois, por certo, ela vingar-se-á de mim, se continuares a

${ }^{19}$ Nep. Eum. 18.6; D. S. 19.11; 49-50; Hyp. Eux. 31-36.

${ }^{20}$ Nep. Eum. 18.6; D. S. 19.11; 49-50; Gell. 13.4; Plu. Alex. 7.8; 39; Curt. 7.1.36-40; Ath. 14.659f-660a. A relação de Olímpia com a epistolografia é uma constante assinalada por quase todos os autores que a ela se referem, o que parece indicar a sua real existência e importância, apesar da possibilidade de as cartas citadas nas fontes conhecidas serem apócrifas. Tendo-se dedicado a escrever cartas, Olímpia demonstra não só ser uma personalidade de interesses políticos definidos, como também, eventualmente, dominar a escrita, o que não seria vulgar para uma mulher, na época. De igual modo, uma célebre resposta dada a Alexandre numa carta exemplifica a sua inteligência política, cf. Mirón 2002, 36-37, 59.

${ }^{21}$ Plu. Alex. 39. Cf. a construção historiográfica da figura de Agripina Menor. Sobre esta questão, ver Girod 2015, esp. 207-28.

${ }^{22}$ D. S. 19.11. A condenação de Olímpia numa assembleia in absentia contribui para essa inglorificação, D. S. 19.51. Não é de excluir, evidentemente, a hipótese de existir algum exagero retórico nas descrições das crueldades de Olímpia, cujo objectivo será o de construir intencionalmente uma determinada imagem; cf. Paus. 8.7.7.

${ }^{23}$ Por exemplo, Curt. 7.1.36-40. Cf. Pimentel 1993. 
admitir nas tuas cartas que sou amante do seu marido.» ${ }^{24} \mathrm{Na}$ verdade, estamos perante uma suave, mas séria, admoestação política, que não deixa de ser uma autoproclamação.

Por outro lado, é inegável que Olímpia assume as suas responsabilidades, desejando um julgamento justo para todo o seu percurso. A justiça não é, mesmo, alheia ao seu carácter, como podemos deduzir do passo de Plutarco em que a rainha reconhece as qualidades de uma rival nos amores com Filipe ${ }^{25}$. Neste sentido, sugere-se também que seria capaz de fazer mudar a opinião da Macedónia, que, ao ouvi-la em assembleia, deduziria a sua importância política, não só pela associação a Alexandre e a Filipe, como também pelas suas capacidades oratórias e retóricas. A composição «virilizada» de Olímpia, a que estas conceções dizem respeito, ganha maior consistência com a descrição da sua presença em campo de batalha, preparada para o confronto com a rival Ádea Eurídice. Analisadas em pormenor, estas referências indicam que Ádea Eurídice era ainda mais «masculinizada» do que Olímpia, mas a princesa epirota não deixa, por isso, de estar à frente de um exército, acabando mesmo por aliciar os soldados adversários para o seu lado, dado o carisma que tinha enquanto rainha da Macedónia. Este aspeto confirma a "virilidade» de Olímpia, uma vez que tais perícias e competências eram fundamentalmente masculinas ${ }^{26}$. $\mathrm{O}$ fator confere-lhe também uma dignidade que acaba por afastar os que estavam encarregados da sua execução, o que, em termos literários, é significativo, pois este seu carácter nobre confere à mãe de Alexandre uma importância suplementar. De igual modo, a morte de Olímpia é descrita por Diodoro obedecendo a essa mesma «virilidade», visto que a rainha morreu sem proferir qualquer tipo de «súplica ignóbil ou feminina», ao mesmo tempo que alcançava a «maior dignidade das mulheres do seu tempo $»^{27}$.

Esta composição masculinizada é também percetível no retrato familiar que dela dá conta esse mesmo Diodoro ao apresentá-la como sempre ligada a «um grande homem $»^{28}$. Posteriormente, reencontraremos figuras em que essa imagética se repete ${ }^{29}$.

Faz também parte desta composição o espírito religioso da rainha, apesar dos traços comuns à comunidade helénica que nele possamos encontrar. Neste domínio, o passo que se conserva nos escritos de Ateneu, no qual a rainha defronta

${ }^{24}$ Gell. 13.4; Plu. Moralia 141c.

${ }^{25}$ Plu. Moralia 141 b-c.

${ }^{26}$ D. S. 19.51. Não será de excluir também alguma associação a Atena, deusa da guerra. Outras mulheres, como Fúlvia e Agripina Maior, foram representadas em situações semelhantes. Vide e.g. Kaplan 1979 et Delia 1991.

${ }^{27}$ D. S. 19.51.

${ }^{28}$ D. S. 19.51 .

${ }^{29}$ Uma vez mais, este é o caso de Agripina Menor, sempre apresentada como mãe, irmã, mulher, sobrinha e neta de imperadores, independentemente das suas capacidades e vocação políticas. 
os exércitos de Ádea Eurídice, é talvez dos mais emblemáticos. Quando nele se conta que Olímpia ia vestida como uma ménade, avançando ao som de uma flauta dionisíaca, enquanto Ádea Eurídice ia de amazona ${ }^{30}$, o texto fornece material para a definição religiosa da mãe de Alexandre, caracterizando-a como uma bacante que surge num campo de batalha. São vários os documentos que apontam para a especial predileção da rainha pelos cultos mistéricos, designadamente pelos de Dioniso e Orfeu. Sabemos, por exemplo, que terá sido quando se iniciava nos mistérios de Samotrácia que terá conhecido Filipe ${ }^{31}$. Este apontamento define Olímpia como alguém que possui uma aura religiosa algo marginal, apesar de, no século IV a.C., na Grécia, o dionisismo já não sofrer da estigmatização de que padecera. Nesta caracterização, Olímpia surge próxima de figuras importantes da literatura grega, também elas de certo modo marginalizadas, como a personagem feminina central das Bacantes de Eurípides, Agave. Associado a esse carácter mistérico, vem um outro não menos marcante e igualmente catalogador: o comportamento associado à imagem da feiticeira, que é um dos parâmetros e tópicos mais recorrentes da definição pejorativa do feminino na Antiguidade. De facto, Olímpia foi acusada de ter usado fármacos para atentar contra a vida de um dos filhos de Filipe ${ }^{32}$. Também aqui Olímpia reencontra a sua natureza marginal, desta vez próxima de personagens como Medeia ou Circe, ou de divindades como Hécate, que, apesar do seu protagonismo e da maior ou menor simpatia que possamos nutrir por elas, não deixam de evocar uma alteridade negativa do feminino na cultura grega. Para a caracterização de Olímpia como personalidade «estranha», porque «estrangeira», contribui também a já aludida lenda, segundo a qual se teria deitado com Zeus, metamorfoseado em serpente, com o que a rainha angaria uma morfologia divina $\mathrm{e}$ ao mesmo tempo perigosa, dado o seu carácter de fronteira/charneira. A associação a serpentes confirma, aliás, tudo o que referimos ${ }^{33}$.

Com Olímpia, estamos sem dúvida longe da conceção da mulher clássica ateniense, silenciosa e recolhida no gineceu, ainda que proveniente das elites, revelando-se um importante grau de emancipação, talvez associado a uma certa pujança económica, que se traduz na influência pública destas figuras ${ }^{34}$.

\section{LAÓDICE I DA SÍRIA}

Outra personalidade em quem é possível detetar este mesmo tipo de caracterização é a rainha Laódice I da Síria. Laódice I era mulher do rei Antíoco

\footnotetext{
${ }^{30}$ Ath. 13.560f; D. S. 19.11.

${ }^{31}$ Plu. Alex. 2.

${ }^{32}$ Mirón 2002, 19; e fontes citadas apud Carney 2006, 92, 105, 179.

${ }^{33}$ Plu. Alex. 2-3.

${ }^{34}$ Mirón 2002, 13. Na verdade, não sendo ateniense e detentora do estatuto de rainha, a sua condição e o seu comportamento político-social seria sempre distinto daquele da esmagadora maioria das atenienses, evidentemente.
} 
II, soberano da dinastia selêucida. É possível que ambos fossem irmãos, mas as fontes não são unânimes quanto a essa eventual relação de parentesco ${ }^{35}$. Outra possibilidade é a de que fossem primos diretos. Desconhecem-se as datas exatas do nascimento e do casamento de Laódice I, mas é verosímil que se tenha casado em 267 a.C. ${ }^{36}$ Como tal, é sensato pensarmos que esta princesa selêucida terá nascido na década de 85 a 75, do século III a.C.

Em 252 a.C., na sequência de um tratado de paz estabelecido com o rei do Egito, Ptolemeu II Filadelfo, Antíoco recebeu como garantia a filha daquele, Berenice, com quem se casou. Como salienta G. Macurdy, este facto deverá significar que Antíoco II se divorciou da esposa anterior, afastando-a assim por razões de natureza política. A ação significava também que, doravante, os filhos de Berenice ganhavam a possibilidade de herdar o trono selêucida, uma vez que a esposa anterior havia sido relegada para segundo plano. Efetivamente, esta nova união era de extrema importância para o equilíbrio das potências que se haviam constituído no Próximo Oriente, após a morte de Alexandre Magno. Pelo seu lado, Laódice era recompensada com propriedades na região da Babilónia e de Borsippa, como recorda uma inscrição cuneiforme da época, ao mesmo tempo que se retirava para Éfeso, na Ásia Menor, juntamente com os seus filhos, Seleuco e Antíoco III ${ }^{37}$.

Mais tarde, porém, a conjuntura política voltou a inverter-se e sabemos que Berenice caiu na desgraça do rei, que recuperou a proximidade com Laódice. Aliás, foi o seu filho Seleuco quem acabou por ser nomeado herdeiro de Antíoco II, em 247 a.C. Surgiu então o rumor de que Laódice havia envenenado o soberano, receando que ele desejasse voltar atrás e assim impedir que o filho de ambos reinasse na Síria. Mas não é certo que isso tenha de facto acontecido ${ }^{38}$.

Laódice recuperou assim o seu estatuto de rainha e recebeu a corregência do reino, uma vez que o filho não atingira ainda os vinte anos. Mas a permanência de Berenice e do filho dela em território selêucida era razão mais do que suficiente para provocar insegurança e incertezas. O pai de Berenice havia então morrido e, no Egito, subira ao trono o irmão dela, Ptolemeu III. Para evitar a possibilidade de Ptolemeu angariar apoios à custa da presença da irmã na Síria, e vice-versa, Laódice decidiu eliminar tanto a rival como o enteado, descendente direto de Antíoco II.

Outro episódio associado à pujança política de Laódice I da Síria é contado por Filarco, o qual é citado por Ateneu. Segundo aquele autor, Láodice tinha uma aia de nome Dánae, filha de uma hetera e discípula de Epicuro, que se havia enamorado de um militar chamado Sófron. Quando Laódice estava em

\footnotetext{
${ }^{35}$ Polyaen. 8.50; Porph. FHG 3.707.

${ }^{36}$ Macurdy 1985, 83.

${ }^{37}$ Ver referências em Macurdy 1985, 83-84.

${ }^{38}$ Cf. App. Syr. 65; Plin. Nat. 7.53; Hier. Expl. Dan. 9:6; V. Max. 9.10 ; Polyaen. 8.50. Macurdy 1985,84 , sugere que esta seja a versão egípcia do acontecimento.
} 
Éfeso, Sófron era a máxima autoridade militar lá instalada. Mas a rainha deposta suspeitava da falta de lealdade de Sófron, pelo que ordenou que o homem se apresentasse perante ela. Dánae estava presente na audiência e, como sabia que a sua senhora tencionava executar Sófron, tentou ajudar o homem de quem gostava, comunicando com ele através de sinais. Sófron percebeu o que se estava a armar e, ajudado por Dánae, conseguiu escapar da audiência, acabando por fugir e aliando-se a Ptolemeu III. Pelo seu lado, tendo resistido a todos os interrogatórios, Dánae foi condenada por Laódice a ser lançada do alto de um rochedo. Quando estava para ser arremessada do promontório, a serva teria dito: «Não admira que os homens desprezem os deuses. Salvei o meu amado, que era para mim como um marido, e é esta a recompensa que o céu me dá. Laódice

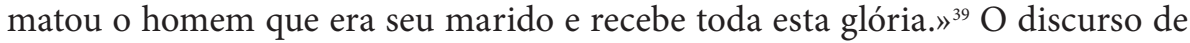
Dánae implica uma retórica historiográfica de influência mitográfica que não era estranha às obras dos autores da época, mas acarreta também uma imagem específica, que pretendemos destacar. O episódio da aia de Laódice sugere, aliás, algo de romanesco, não sendo impossível que se trate precisamente disso: de uma historieta inserida na narrativa da rainha, com o objectivo de dar dela uma determinada impressão ${ }^{40}$. Se a tradição que reclamava a culpa do envenenamento de Antíoco II para Laódice associava também a rainha ao assassínio de Berenice do Egito e do seu filho, a história de Dánae recupera essa imagem e constrói a de uma rainha cruel, que serve de braço armado para a aplicação dos caprichos divinos que fazem com que os Homens não passem de joguetes. Mas não deixa de ser igualmente impressionante o sentido de justiça da rainha, que não hesita em castigar implacavelmente a traição de uma amiga com a morte dela.

Assim, a atitude claramente política leva a retratar Laódice com a mesma força de personalidade que havíamos antes encontrado em Olímpia da Macedónia. Muitos dos historiadores antigos condenaram Laódice pela sua crueldade, enquanto outros, ainda que poucos, tenham preferido reconhecer nela a força da necessidade pontual de afastar os rivais, em defesa da própria vida e da dos seus filhos ${ }^{41}$. Assim se justifica a eliminação de Berenice e do seu herdeiro, bem como a de Dánae. Neste sentido, também Laódice I da Síria surge como uma femina politica de carácter bem definido.

Apesar de pouco mais sabermos acerca desta mulher, um passo de Plutarco permite-nos deduzir que, durante a guerra que opôs os seus dois filhos, mais tarde, Laódice se manteve ao lado do mais novo, Antíoco, então com apenas catorze anos de idade, contra o mais velho, Seleuco ${ }^{42}$. Alguns autores sugerem que a intenção de

\footnotetext{
${ }^{39}$ Ath. 13.593; FHG 1.339.

${ }^{40}$ Este tipo de artifício estava em voga na época, como atesta Braun 1938.

${ }^{41}$ Macurdy 1985, 85. Processo semelhante é o que encontramos, e.g., na composição da figura de Messalina. Sobre este caso, ver Rodrigues 2003.

${ }^{42}$ Plu. Mor. 489a.
} 
Laódice ao associar-se ao filho mais novo terá sido a de tentar precisamente controlar o jovem, conseguindo desse modo manter-se mais próxima da política do que aconteceria no caso de Seleuco subir ao trono. Se assim foi, também Laódice recorreu ao argumento da «rainha-mãe» para atingir os seus objetivos políticos. Apiano refere que Laódice foi morta por Ptolemeu III, apesar de alguns historiadores colocarem o «facto» em dúvida ${ }^{43}$. O certo é que o seu prestígio na Antiguidade foi de tal modo grande que, a partir dela, várias rainhas receberam o seu nome ${ }^{44}$.

\section{BERENICE I DO EGITO}

Entre os Lágidas, encontramos também alguns nomes em que se reconhecem as características até agora enunciadas. O primeiro deles é Berenice I do Egito, casada com Ptolemeu I Sóter, em finais do século IV a.C. São muitos e complexos os problemas historiográficos colocados em torno desta rainha, desde a data do seu nascimento, tido por alguns no ano de 340 a.C., à relação consanguínea que teria, ou não, com o marido. Não é nosso objectivo tratá-los neste pequeno estudo ${ }^{45}$. Desejamos, em vez disso, salientar a atuação política da soberana. Toda a prole de Berenice assumiu cargos importantes na política do seu tempo. Foi o filho dela que sucedeu a Ptolemeu I Sóter, em 284 a.C., e não o primogénito deste, nascido de outra princesa, de nome Eurídice. Isso mostra que a influência de Berenice foi significativa e não é de descartar a hipótese de ela se ter feito, uma vez mais, nos bastidores da política, em que dominavam as rainhas-mães. Além disso, o poeta Teócrito testemunha a boa relação que existia entre a rainha e o rei do Egito ${ }^{46}$. De igual modo, a sua filha mais velha, Arsínoe II, casou-se com o irmão e também ela veio a ser rainha do Egito. Apesar de nunca se ter casado, a terceira filha de Berenice, chamada Filótera, recebeu altas honras dos irmãos. Antígona, a quarta filha, casou-se com Pirro, em 298 a.C., e o seu filho Magas veio a ser rei de Cirene. Como nota G. Macurdy, dificilmente estas alianças se teriam feito se Berenice não fosse tida como um elemento politicamente importante na casa real lágida ${ }^{47}$. Efetivamente, Teócrito elogia a sabedoria de Berenice e Plutarco refere-se mesmo ao poder intelectual da rainha, destacando-a no quadro político coevo. É também isso que explica o facto de Berenice I ter recebido, juntamente com o marido, o título de «Sóter» ou «Salvadora», «A que salva» ou "A que protege», e com ele alcançado também a apoteose, com direito a um templo próprio na cidade de Alexandria, o Bereniceum ${ }^{48}$.

\footnotetext{
${ }^{43}$ App. Syr. 65; cf. Macurdy 1985, 86.

${ }^{44}$ Sobre esta rainha ver ainda Ogden 1999, 119-24.

${ }^{45}$ Ver, por e.g., Macurdy 1985, 104-9.

${ }^{46}$ Theoc. 17.

${ }^{47}$ Macurdy 1985 106-107.

${ }^{48}$ Ath. 5.202D; Ogden 1999, 61, 68-73, 215-17.
} 


\section{Arsínoe II do Egito}

Mas, entre os Lágidas, outras mulheres se destacam como figuras de proa no contexto político do seu tempo. A já mencionada Arsínoe II é outro exemplo a ser considerado. Também esta, nascida em 315 a.C., era uma mulher de sangue macedónico, visto que era irmã daquele que veio a ser seu marido, Ptolemeu II Filadelfo do Egito. Filha de Berenice I e de Ptolemeu I Sóter, Arsínoe II começou a sua carreira política ao casar-se com o rei da Trácia, Lisímaco, um dos diádocos. Aí, a princesa lágida ter-se-á envolvido numa história de contornos românticos, como sugerem alguns historiadores, em que se percebem elementos do tema de Fedra e Hipólito, contudo verosímil ${ }^{49}$. Seja como for, ter-se-á criado e difundido a ideia de que a rainha da Trácia teria tentado envenenar o velho marido, por se ter apaixonado pelo jovem filho dele, Agátocles. Tal contexto teria granjeado a Arsínoe uma fama pouco simpática, de que o epíteto «Penélope de Lisímaco» seria a expressão mais irónica ${ }^{50}$. As peripécias que se contam na sequência de tais atos políticos não são menos pejorativas para a rainha. Uma das menos elogiosas narra como, para escapar às tropas de Seleuco, Arsínoe teria ordenado que uma das criadas envergasse os seus vestidos, para que desse modo a serva fosse confundida com a rainha e assim executada em vez de ela própria $^{51}$. Disfarçando-se de mendiga, Arsínoe conseguiu então embarcar e fugir para a Macedónia ${ }^{52}$. Uma vez aí, com a ajuda do meio-irmão, Ptolemeu Cerauno, Arsínoe veio a ser aclamada rainha do território. Mas a sua alegria durou pouco, uma vez que Cerauno acabou por eliminar dois dos três filhos da antiga rainha da Trácia, ao mesmo tempo que o terceiro conseguia fugir para a Ilíria ${ }^{53}$. Muito provavelmente, Arsínoe apenas escapou às armas do irmão, porque este terá temido uma vingança proveniente de Alexandria ${ }^{54}$.

Depois da derrota de Ptolemeu Cerauno às mãos dos Gauleses, Arsínoe fugiu para a Samotrácia e daí para o Egito. Apesar de aclamada rainha entre os Macedónios, foi apenas no país do Nilo que esta lágida acabou por concretizar o exercício efetivo do poder político, cujo clímax se verificou no facto de ter sido a primeira mulher macedónia a receber a divinização ainda em vida ${ }^{55}$. A sua conquista do poder foi paulatina, e não sem desaires pessoais, mas eficaz. Começou por afastar a enteada e cunhada do poder e, entre 276 e 275 a.C., casou-se com o irmão, Ptolemeu II Filadelfo. Deste modo, a dinastia lágida recuperava o costume da união

\footnotetext{
${ }^{49}$ Efetivamente, a influência de Eurípides parece ser grande na composição deste episódio. Sobre a sua verosimilhança, ver Macurdy 1985, 113; Ogden 1999, 61.

${ }^{50}$ Cf. Plu. Dem. 25.

${ }^{51}$ A história de Acerrónia, em Tac. Ann. 14.5, tem contornos semelhantes aos desta narrativa.

${ }^{52}$ Polyaen. 8.57.

${ }^{53}$ Just. 17.2.7-9; 24.2-3.

${ }^{54}$ Macurdy 1985, 115.

${ }^{55}$ Ver documentos citados em Macurdy 1985, 128-29; ver ainda Longega 1968; Carney 2013.
} 
fraternal, praticada no Antigo Egito, como expressa no mito de Ísis e Osíris, mas até então inusitada entre Macedónios e Gregos em geral ${ }^{56}$. Apenas hierogamias, como a de Zeus e Hera ${ }^{57}$, davam conta dela, correspondendo por certo a um fundamento ritual antigo. A intenção terá sido, claramente, a apropriação do poder, ao mesmo tempo que se encetava uma forma de propaganda política grega no Oriente, até então desconhecida, que granjearia apoios populares e, muito em especial, das classes sacerdotais. O êxito de tal manobra foi tal, que até mesmo Teócrito, motivado talvez pela necessidade de manter o patrocínio régio ou pelo envolvimento no contexto político de então, elogia a união incestuosa como uma réplica da hierogamia grega mais conhecida ${ }^{58}$. Esta decisão juntamente com a divinização em vida são, como é evidente, a assunção de costumes orientais e, para alguns historiadores, o seu aproveitamento ter-se-á feito por iniciativa da própria Arsínoe ${ }^{59}$.

É hoje indiscutível que Arsínoe II participou, directa ou indiretamente, no afastamento e eliminação de adversários políticos. Há, contudo, que não olvidar a prática da época, em que a eliminação física era um recurso habitual na administração dos poderes. De qualquer modo, é significativo que Arsínoe assuma esse papel, o qual costumava ser mais facilmente atribuído a personalidades masculinas. Na realidade, na análise que temos vindo a expor, verificamos um padrão de comportamento relativamente às mulheres sob estudo e respetivos contextos sociopolíticos.

Mas, a partir de algumas fontes antigas, é possível perceber também que esta rainha lágida não se limitou às intrigas de corte. Efetivamente, em 273 a.C., acompanhou o marido a Heroópolis, numa campanha de inspeção dos mecanismos de defesa da fronteira egípcia. Outros documentos dão-na como instigadora de diretrizes políticas, que vieram a ser aproveitadas pelo próprio marido. O recurso à sua imagem por parte de poetas como Teócrito, que para ela cultivaram formas de adulatio, comprova também a sua importância. Este conjunto de elementos permite, portanto, a inserção de Arsínoe II no grupo das politicamente ativas rainhas helenísticas ${ }^{60}$. Esta soberana faleceu em 270 a.C.

${ }^{56}$ Macurdy 1985, 117, nota que, tanto na Macedónia como na Grécia, se tolerava a união de irmãos não uterinos, o que não era o caso de Arsínoe e Ptolemeu II Filadelfo. Theoc. 12, 5, chama a Arsínoe «três vezes esposa».

${ }^{57} \mathrm{Il}$. 14.224-353.

58 Theoc. 14.

${ }^{59}$ Macurdy 1985, 118. O que poderá ser discutível, visto que a evidência da utilidade política desta prática é tão grande que atribuí-la a Arsínoe poderá não passar de especulação parcial.

${ }^{60}$ Documentação citada por Macurdy 1985, 119, 126-27. Uma síntese da atuação política de Arsínoe II pode ser lida nesta mesma obra, 111-130. A este propósito, vale a pena citar Macurdy: «Arsinoe had beauty and intellect. She appears to have been one of the greatest administrative women who have ever lived and she had all conceivable honors. It is difficult to call her a good woman. I believe that no record of a single good deed on her part has been handed down to us. In her energy, political foresight, and utter unscrupulousness the Gods made her to match the men of her time», (ibid. 130). Ver também Longega 1968; Ogden 1999, 57-62; Carney 2013. 


\section{Cleópatra VII do Egito}

Para finalizar este breve périplo pelas personalidades femininas que dominaram o período helenístico em termos políticos, e que contribuíram para uma nova perceção das mulheres na cultura grega, condicionando desse modo a sua interpretação ocidental, citamos ainda o exemplo de Cleópatra VII Filopator ${ }^{61}$. Esta figura foi por nós já estudada, sobretudo a partir de duas das principais fontes que acerca dela fornecem informações: Flávio Josefo e Plutarco ${ }^{62}$. Sendo estes dois autores centrais na caracterização da última rainha dos Ptolemeus, encontramos neles os elementos fundamentais que permitem o eixo principal na definição desta mulher.

Nascida em 69 a.C., Cleópatra VII era uma das filhas de Ptolemeu XII Auletes. Depois da morte deste, em 51 a.C., sucedeu-lhe o filho Ptolemeu XIII, ainda muito jovem, que, entretanto, se casara com a irmã Cleópatra, segundo o costume que então se tinha já instituído no Egito lágida. O casamento dos dois irmãos, contudo, não passou de uma aliança política, em que rapidamente se perceberam as forças e interesses em confronto. Em 48 a.C., Cleópatra foi afastada do poder pelos partidários do irmão, mas Júlio César, que na ocasião se encontrava no Egito, na sequência da guerra com Pompeio, interveio no processo, apoiando os interesses da rainha lágida. No decurso das Guerras Alexandrinas, que então eclodiram, Ptolemeu XIII perdeu a vida e Cleópatra assumiu o poder no Egito como legítima herdeira dos Lágidas. Para isso, contudo, desposou o mais novo dos seus irmãos, Ptolemeu XIV.

A relação que terá desenvolvido com o general romano foi um dos grandes apoios que a rainha encontrou para a manutenção o seu poder. A ideia de que César poderá ter sido o pai do primeiro filho de Cleópatra reforça essa tese, ainda que haja autores que ponham em causa tal paternidade ${ }^{63}$. Seja como for, em 46 a.C., Cleópatra seguiu Júlio César até Roma, acabando por regressar ao Egito apenas após o assassínio do general romano. Pouco depois, morreu Ptolemeu XIV, talvez envenenado pela própria irmã ${ }^{64}$. Em 41 a.C., a rainha aliou-se a Marco António, o oficial romano que representava os interesses de César, e a proximidade entre ambos tornou-se de tal modo significativa que, em 32 a.C., Octávio declarou guerra à soberana do Egito, tendo como objectivo, evidente, afastar definitivamente António das pretensões ao poder em Roma. À Urbe, chegavam boatos de que a rainha greco-egípcia se vangloriava de controlar os destinos do Capitólio ${ }^{65}$. Os filhos que ela tivera do tribuno romano só ajudaram

\footnotetext{
${ }^{61}$ Sobre as várias Cleopatras helenísticas, vide Macurdy 1937, 7-18; Whitehorne 1994.

${ }^{62}$ Cf. Rodrigues 1999, 217-59; Rodrigues 2002, 127-49; Rodrigues 2011; Rodrigues 2012; Rodrigues 2013.

${ }^{63}$ Vide e.g. Goldsworthy 2006, 604-5; Goldsworthy 2010, 220-21.

${ }^{64}$ I. AI 15.89; Roller 2010, 74-75.

${ }^{65}$ Ver remissão para fontes em Hughes-Hallet 1990, 64-82; Walker e Higgs 2001; Jones 2006;
} 
Octávio a formular as declarações de guerra. O confronto das forças em causa deu-se em Áccio, no ano 31 a.C. António e Cleópatra foram derrotados e, em 30 a.C., perante a possibilidade de se terem de humilhar a Octaviano e a Roma, ambos optaram pelo suicídio.

Também a história de Cleópatra VII está repleta de pormenores que favorecem o romanesco e o novelesco, e que os historiadores devem usar com cautela ${ }^{66}$. Mas são esses mesmos elementos que permitem, em grande parte, a construção de uma determinada imagem da última rainha helenística e que a coloca na sequência dos exemplos anteriormente citados. Por outro lado, apesar de quaisquer histórias que se contem acerca de Cleópatra VII, é evidente que ela foi suficientemente importante para inquietar os Romanos e o seu Estado.

De facto, a construção de Cleópatra como femina politica é o primeiro objectivo dos autores que acerca dela escreveram ${ }^{67}$. Para a concretização dessa imagem, a Cleópatra são atribuídas atitudes e opções viris, que a masculinizam e a fazem contrastar com as personagens femininas consideradas ideais, de que Octávia, mulher de António, é o paradigma, bem como ações que, no campo amoroso, ultrapassam o limite da temperança ${ }^{68}$. Essa definição é conseguida graças a características como o domínio do poder e a ambição, ou por atributos que a transformam numa figura malquista: má anfitriã, traidora, lasciva, impiedosa, mentirosa, eroticamente ativa e sedutora, tentando dominar o oculto através da feitiçaria, manifestando alguma loucura, exibindo crueldade e assumindo-se mesmo como assassina ${ }^{69}$. Todas estas características são percetíveis nos autores que acerca dela escreveram ou deixaram registos. É mesmo evidente que muitas delas se aproximam do que analisámos relativamente a Olímpia da Macedónia, uma das suas «antepassadas». O que equivale a dizer que a última das lágidas é uma reedição da primeira das rainhas helenísticas. Isto é, Cleópatra VII Filopator completa um ciclo de imagens inaugurado pela mãe de Alexandre e que, sem dúvida, alterou definitivamente a forma de olhar o feminino na cultura grega e, por consequência, na cultura ocidental.

Com efeito, quando as Actas do julgamento que condenou à morte Maria Antonieta, Arquiduquesa da Áustria e Rainha de França, se referiam à mulher comparável «às perversas rainhas da Antiguidade», quem estaria no imaginário daqueles juízes senão mulheres como estas? ${ }^{70}$

\footnotetext{
Ashton e Walker 2006.

${ }^{66}$ Hughes-Hallet 1990.

${ }^{67}$ Becher 1966.

${ }^{68}$ Rodrigues 2012; Rodrigues 2013.

${ }^{69}$ Cf. Rodrigues 1999, 217-59; Rodrigues 2002, 127-49; Rodrigues 2011; Rodrigues 2012; Rodrigues 2013.

${ }^{70}$ Lever 2000, 334.
} 


\section{EM SUMA}

Sendo o período helenístico o do encontro das culturas orientais e europeias, favorecido ao nível das elites, e não só, pela rede de casamentos que então se estabeleceu, é inevitável considerar que a ideia de alteridade ganhou espaço considerável com essa convergência ${ }^{71}$. Efetivamente, no Próximo Oriente Antigo, encontramos elementos suficientes para que se estabeleça uma comparação viável com esta nova forma de olhar a mulher, que se define como "Outra» tanto pelo género a que pertence, como pelo ambiente cultural em que germina. Assinalámos os casos das rainhas-mães, que encontraram um espaço próprio e omnipresente nas literaturas orientais antigas. Mas podemos acrescentar outros modelos que poderão ter surgido como referências a autores como Josefo, ao reconstruírem a história de uma soberana como Cleópatra, por exemplo. Casos como os de Dalila, Atália e Jezabel poderão ter estado subjacentes à sua composição. Possivelmente, trata-se de um produto da influência da literatura e cultura orientais, com as quais os Gregos passaram a ter a possibilidade de se familiarizarem. Por outro lado, para um grego, a ideia de Cleópatra como uma «reencarnação» de outra lendária rainha oriental, Ônfale, como evoca Plutarco, não seria de todo despropositada ${ }^{72}$. Que outros modelos poderão ter estado subjacentes às composições que assinalámos? Sugerimos paralelos com personagens da cultura grega, como Hécate, Medeia, Circe e Fedra, e parece-nos evidente que os Gregos olhariam para estas rainhas tendo estes e outros caracteres como referências. Compará-las-iam a Penélope, figura presente, mas discreta, ou a Clitemnestra, protótipo da imagem feminina negativa $^{73}$. Ou recorreriam mesmo à História e teriam como matrizes Safo ou Aspásia. Ao seu modo, míticas ou reais, essas mulheres tinham ajudado a construir, como por ela tinham sido "construídas», uma determinada ideia de feminino. Rejeitadas ou aceites como modelos de comportamento, é no Helenismo que descobrimos a mulher que começa a ser de facto autónoma, que se permite a conduzir destinos políticos. Se as anteriores indicaram o caminho, é com as rainhas helenísticas que se concretiza a ação e isso traduz uma mudança social, política e mental que permitiu, se não os factos, que não negamos, pelo menos a sua imagem e representação. Neste campo, haveria que saber qual era de facto a verdadeira ação da mulher ateniense, no século V, por exemplo. Seria mesmo como por vezes se pretende? Por outro lado, há que não esquecer que a «História escrita pelos vencedores» conduziu a uma anatematização do feminino.

É verdade que, já antes, os textos gregos tinham dado a conhecer mulheres interventoras. Já referimos a obra de Heródoto como caso, em que surgem exemplos paradigmáticos, como Artemísia e Tómiris. Mas a novidade é que

\footnotetext{
${ }^{71}$ A este propósito, recordemos as chamadas Bodas de Susa, Plu. Alex. 36, 37, 70; Eum. 1.

${ }^{72}$ Plu. Ant. 90, 4. Já Aspásia o fora, na biografia de Péricles, Per. 24.9.

${ }^{73}$ Rodrigues 2010.
} 
as mulheres agora intervenientes na vida pública não são mais exclusivamente bárbaras. Efetivamente, a rainha helenística é grega de origem ou, pelo menos, falante de grego, sendo esta a língua de uma cultura essencialmente androcêntrica. A rainha helenística tornou-se, contudo, mais do que isso ao viver a sua experiência no espaço não-grego. Essas mulheres alimentaram-se das vivências culturais do Outro e redefiniram-se, tornando-se figuras politicamente ativas, a que os historiadores gregos imprimiram doses de reprovação e censura. Trata-se de um novo paradigma de feminino para o modelo imperial que se começava a definir no horizonte, perante e a partir de matrizes e modelos como Penélope, Lucrécia ou Cornélia, a mãe dos $\operatorname{Gracos}^{74}$.

Naquelas, é igualmente impossível não reconhecer a inovação e a diferença no caminho de uma emancipação até então estranha. Como a esfinge, criatura da mitologia, concebida de uma ideia oriental, mas que ganhou vida no espaço helénico, também estas mulheres se deixaram representar através de esculturas e efígies que obedeceram a cânones classicizantes ${ }^{75}$, mas comportando-se como liberdade de ação nova, que, no entanto, se insere no espírito helenístico da oikoumene. Aparentemente, muitos dos seus contemporâneos conviviam já muito bem com essa «novidade». Assim, apesar das mudanças que o medievo trouxe à História da Europa, parece-nos indiscutível que neste espaço e tempo helenísticos se processaram alterações e mudanças de perspetiva que alteraram para sempre as formas de olhar a mulher.

\footnotetext{
${ }^{74}$ Ver Rodrigues 2005.

${ }^{75}$ Cf. Sales 2005.
} 


\section{Bibliografia}

Amaral, A. L. 1994. "Duas rainhas em Heródoto: Tómiris e Artemísia." Humanitas 46:1741.

Andreasen, N. A. 1993. "The role of the Queen Mother in the Israelite society." Catholic Biblical Quarterly 45 (2):186-90.

Araújo, L. M. 2001. “Esfinge.” In Dicionário do Antigo Egito, coord. L. M. Araújo, 337. Lisboa: Editorial Caminho.

Ashton, S. e S. Walker. 2006. Cleopatra. London: Duckworth / Bristol Classical Press.

Becher, I. 1966. Das Bild der Kleopatra in der griechischen und lateinischen Literatur. Berlin: Akademie-Verlag.

Ben-Barak, Z. 1987. “The Queen consort.” In La femme dans le Proche Orient antique, ed. J.-M. Durand, 30-52. Paris: Éditions Recherche sur les civilisations.

Braun, M. 1938. History and Romance in Graeco-Oriental Literature. Oxford: Blackwell.

Carney, E. D. 2013. Arsinoë of Egypt and Macedon: a Royal Life. Oxford: Oxford University Press.

—_.2006. Olympias, Mother of Alexander the Great. London: Routledge.

—_. 2000. Women and Monarchy in Macedonia. Norman: University of Oklahoma Press.

Delia, D. 1991. "Fulvia Reconsidered." In Women's History and Ancient History, ed. S. B. Pomeroy, 173-96. London / Chapel Hill: University of North Carolina Press.

Girod, V. 2015. Agrippine. Sexe, crimes et pouvoir dans la Rome impériale. Paris: Tallandier.

Goldsworthy, A. 2010. Antony and Cleopatra. London: Phoenix.

Goldsworthy, A. 2006. Caesar. The Life of a Colossus. London: Phoenix.

Hughes-Hallett, L. 1990. Cleopatra. Histories, Dreams and Distortions. London: Bloomsbury.

Jones, P. J. 2006. Cleopatra: A Sourcebook. Norman: University of Oklahoma Press.

Kaplan, M. S. 1979. "Agrippina semper atrox: A Study in Tacitus'Characterization of Women." In Studies in Latin Literature and Roman History, ed. C. Deroux, 410-17. Turnhout: Latomus.

Lever, E. 2000. Marie Antoinette: The Last Queen of France. New York: Portrait. Longega, G. 1968. Arsinoe II. Roma: "L’Erma” di Bretschneider.

Macurdy, G. H. 1985. Hellenistic Queens. A Study of Woman-Power in Macedonia, 
Seleucid Syria, and Ptolemaic Egypt. Chicago: Ares Publishers.

Macurdy, G. H. 1937. Vassal-Queens and Some Contemporary Women in the Roman Empire. Baltimore: Johns Hopkins Press.

Mirón, D. 2002. Olimpia (ca. 373-316 a.V.). Madrid: Ediciones del Orto.

Ogden, D. 1999. Polygamy, Prostitutes and Death. The Hellenistic Dynasties. London: Duckworth / The Classic Press of Wales.

Pimentel, M. C. 1993. “Quo uerget furor?” Aspectos estóicos na Phaedra de Séneca. Lisboa: Colibri.

Rodrigues, N. S. 2013. "Amimetobiou, the One "of the Inimitable Life": Cleopatra as a Metaphor for Alexandria in Plutarch." In Alexandrea ad Aegyptum. The Legacy of Multiculturalism in Antiquity, ed. R. Sousa, M. C. Fialho, M. Haggag e N. Simões Rodrigues, 58-69. Porto: Edições Afrontamento / Centro de Investigação Transdisciplinar "Cultura, Espaço \& Memória".

2012. "Nomos e kosmos na caracterização do António e da Cleópatra de Plutarco." In Nomos, Kosmos \& Dike in Plutarch, eds. J. Ribeiro Ferreira, D. F. Leão e C. A. Martins de Jesus, 101-8. Coimbra: Classica Digitalia/ / Centro de Estudos Clássicos e Humanísticos.

— 2011. “A “Da Vida Inimitável." A Cleópatra de Plutarco como Metáfora oriental". Calíope 22:82-97.

_ 2010. "Ainda Clitemnestra, a «mulher de máscula vontade»" Cadmo 20:393-405.

-2005. "A heroína romana como matriz de identidade feminina." In Mito clássico no Imaginário Ocidental, coord. D. F. Leão, M.C. Fialho e M.F. Silva, prefácio M. Cláudio, 67-85. Coimbra: Ariadne Editora.

. 2003. "Messalina ou Aphrodita tragica in Vrbe." In Presença de Victor Jabouille, org. A. Ventura, 513-34. Lisboa: Faculdade de Letras da Universidade de Lisboa.

— 2002. "Plutarco, historiador dos Lágidas: o caso de Cleópatra VII Filopator." In Actas do Congresso "Plutarco educador da Europa", coord. J. Ribeiro Ferreira, 127-49. Porto: Fundação Eng. A. Almeida.

. 1999. “O Judeu e a Egípcia: o retrato de Cleópatra em Flávio Josefo.” Polis. Revista de Ideas y Formas Políticas de la Antigüedad Clásica 11:21759.

Roller, D. W. 2010. Cleopatra. A Biography. Oxford: Oxford University Press.

Sales, J. C. 2005. Ideologia e propaganda real no Egito Ptolomaico (305-30 a.C.). Lisboa: Fundação Calouste Gulbenkian / Fundação para a Ciência e Tecnologia.

Tavares, A. A. 1998. "A mulher nas lutas pela sucessão do poder real no Médio Oriente Antigo." In, Poder e Sociedade. Da Antiguidade ao período 
Peri Basilissas. Em torno da importância política de cinco rainhas helenísticas

contemporâneo (Actas das Jornadas Interdisciplinares), org. M. J. Ferro Tavares, 15-28. Lisboa: Universidade Aberta.

Walker, s. e P. Higgs. 2001. Cleopatra of Egypt: From History to Myth. London: British Museum Press.

Waterfield, R. 2011. Dividing the Spoils: The War for Alexander the Great's Empire. Oxford: University Press.

Whitehorne, J. 1994. Cleopatras. London / New York: Routledge. 